\title{
Original
}

\section{Comparison of Mid-term Angiographic and Clinical Outcomes Following Zotarolimus-eluting Stent and Paclitaxel-eluting Stent Implantation Based on Lesion Complexity}

\author{
Seita Kondo, Yuji Hamazaki, Tenjin Nishikura, \\ Hiroyuki Yokota, Hiroaki Tujita, Satoshi Hosokawa, \\ Shigeto Tsukamoto, Mitsunori Muto, Masayuki Sakurai, \\ Hideki Nishimura, Takeshi Kondo and Youichi Kobayashi
}

\begin{abstract}
First-generation drug-eluting stents (DESs) have reduced angiographic and clinical restenosis rates compared to bare-metal stents (BMSs). Zotarolimus-eluting stents (ZESs) are second-generation drug-eluting stents: however, the clinical efficacy of ZES implantation is unclear because late loss associated with ZESs is reportedly higher than that observed for other DESs. The aim of this study was to evaluate the clinical efficacy of ZESs compared to paclitaxel-eluting stents (PESs). We retrospectively evaluated the angiographic and clinical outcomes of 431 lesions in 342 patients treated with PESs and 153 lesions in 121 patients treated with ZESs in our hospital between May 2007 and December 2010. Follow-up angiographic examinations were performed eight months post-treatment and clinical outcomes were assessed one year after the procedure. Quantitative coronary angiographic analyses showed that late loss was significantly higher for ZESs than PESs $(0.82 \pm 0.73 \mathrm{~mm}$ vs $0.47 \pm$ $0.68 \mathrm{~mm} ; P=0.003)$. However, there was no significant difference in target lesion revascularization (TLR) between the two groups (ZES: 15 lesions, 9.8\% vs PES : 25 lesions, 5.8\%; $P=0.092)$. When comparing stents according to the American College of Cardiology/American Heart Association (ACC/ AHA) lesion type, the TLR rate in the ZES group was significantly lower than in the PES group ( $0 \%$ vs $7.0 \% ; P=0.038)$ for Type A/B1 lesions, but the TLR rate for type $\mathrm{B} 2 / \mathrm{C}$ lesions in the ZES group was significantly higher than in the PES group $(15.8 \%$ vs $5.3 \% ; P=0.009)$. Multivariate logistic regression analysis showed that dialysis (OR : 35.54; 95\% CI : 3.15-400.67; $P=0.039$ ) and pre-minimal lumen diameter (OR : $0.036 ; 95 \% \mathrm{CI}: 0.002$ $0.541 ; P=0.016)$ were independent predictors of TLR in ZES-treated lesions. However, no factors predicted TLR in PES-treated lesions. Our study demonstrated excellent outcomes with ZESs for simple lesions, but it is necessary to carefully implant ZESs in complex lesions, such as ACC/AHA type B2 / C lesions..
\end{abstract}

Key words : Target lesion revascularization, drug-eluting stent, Zotarolimuseluting stent, Paclitaxel-eluting stent, lesion complexity

Department of Medicine, Division of Cardiology, Showa University School of Medicine, 1-5-8 Hatanodai, Shinagawaku, Tokyo 142-8666, Japan. 


\section{Introduction}

Previous studies have reported that patients treated with first-generation drug-eluting stents (DESs) had improved angiographic and clinical outcomes compared to those treated with bare-metal stents (BMSs) ${ }^{1,2)}$. Zotarolimus-eluting stents (ZESs ; Endeavor, Medtronic CardioVascular, Santa Rosa, CA, USA) are second-generation drug-eluting stents that deliver the potent anti-proliferative agent zotarolimus through a biocompatible phosphorylcholine polymer, that has a shorter drug-elution time (within two weeks), on a cobalt chromiumbased thin-strut (0.0036") stent $^{3,4)}$. ZESs have been available in Japan since May 2009, and treatment with ZESs is associated with significant reductions in angiographic restenosis and target lesion revascularization (TLR) compared to treatment with $\mathrm{BMSs}^{5,6}$. However, the clinical efficacy after implantation of ZESs remains unclear because the late loss associated with ZESs is reportedly higher than that associated with other DESs ${ }^{7)}$. Limited information is available about the angiographic and clinical outcomes of first-generation DESs and ZESs, and few studies have focused on the impact of differential lesion complexity on the efficacy of these treatments ${ }^{3,8)}$. The aim of this study was to evaluate and compare the clinical efficacies of the second generation DES, ZES, and the paclitaxel-eluting stent (PES; TAXUS, Boston Scientific Corporation, Natick, MA, USA), a first-generation DES. Furthermore, we performed a stratified analysis according to lesion complexity and compared the efficacies of ZESs and PESs in complex lesions, which were defined as type B2/ C lesions, and in simple lesions, which were defined as type A/B1 lesions.

\section{Methods}

\section{Study population}

We retrospectively evaluated the angiographic and clinical outcomes of 431 lesions in 342 patients treated with PESs and 153 lesions in 121 patients treated with ZESs in daily practice between May 2007 and Dec 2010 at our hospital. Follow-up angiographic examinations were performed eight months post-treatment and clinical outcomes were assessed one year after the procedure.

\section{Angioplasty procedures}

All procedures were performed with a 7- or 8-French-gauge guiding catheter and a femoral approach. Stents were deployed with or without predilatation according to standard techniques. In all cases, the stent was placed so that its entire length covered the lesion, and dilation pressure was applied to the stent until the lesion was sufficiently dilated under transillumination. Intravascular ultrasound (IVUS) was used in all cases during predilatation to determine stent diameter, and following stent deployment and post-dilatation to check stent apposition. After stent implantation, aspirin (at least $100 \mathrm{mg} /$ day) was prescribed for an indefinite duration, and clopidogrel $(75 \mathrm{mg} /$ day $)$ or ticlopidine (200 $\mathrm{mg} /$ day) was 
administered for at least 12 months.

\section{Definitions}

Anginal symptoms were defined according to the Canadian Cardiovascular Society classification. Major adverse cardiac events (MACE) were defined as death from any cause, myocardial infarction (MI), or TLR. TLR was defined as any repeat revascularization procedure (percutaneous or surgical) of the original target lesion site. Target vessel revascularization was defined as clinically driven percutaneous revascularization or bypass of the target lesion or any segment of the epicardial coronary artery containing the target lesion. Acute coronary syndrome (ACS) was defined as acute myocardial infarction or unstable angina pectoris. A calcified lesion was defined as an identifiable radiopaque image in the case of still images obtained before injecting contrast agent or an identifiable dark image on moving images. Lesions longer than $20 \mathrm{~mm}$ were defined as long lesions. Target restenosis was defined as stenosis of $50 \%$ or more based on follow-up remote-phase coronary angiography results. In addition, we defined type A/B1 lesions as "simple” lesions and type B2/ C lesions as "complex" lesions.

Quantitative coronary angiography (QCA) was performed with the QCA-CMS cardiovascular analysis system manufactured by Medis. Lesion length, minimum vascular diameter, and control vascular diameter were measured from the dilated phase frames, and all measurements were taken from an angle showing minimal lesion contraction. The same angles were used in pre-treatment, post-treatment, and follow-up remote-phase coronary angiography. The rate of stenosis, acquired inner diameter in the acute phase, and loss of inner diameter in the remote phase were then calculated.

\section{Statistical analysis}

Quantitative data are presented as the mean $\pm \mathrm{SD}$, and categorical data are presented as percentages. Statistical analysis was performed using the chi-square test or Fisher's exact test (two-tailed) for categorical variables. Student's $t$-tests were used for the comparison of continuous variables, and $P$ values of 0.05 or less were considered significant. Univariate and multivariate analyses of continuous ratios, including 95\% confidence intervals (CI), were calculated using the Cox proportional hazards model. Factors with $P$ values less than 0.05 in the univariate analysis were entered into the multivariate model. Statistical analysis was performed using commercially available software.

\section{Results}

Baseline patient characteristics were similar among all ZES and PES patients except for the higher percentages of dialysis and smoking in the PES group $(P=0.028$ and $P=0.002$, respectively) and the higher percentage of ACS in the ZES group $(P<0.0001$; Table 1$)$.

Lesion characteristics and quantitative angiographic analysis data are listed in Table 2. 
Table 1. Baseline characteristics of all patients

\begin{tabular}{|c|c|c|c|}
\hline & ZES & PES & $P$ value \\
\hline Patients, $\mathrm{n}$ & 121 & 342 & \\
\hline Age, years & $66.35 \pm 12.71$ & $67.35 \pm 10.26$ & 0.386 \\
\hline Male gender, n (\%) & $95(78.5)$ & $273(79.8)$ & 0.759 \\
\hline \multicolumn{4}{|l|}{ Risk factor } \\
\hline Hypertension, n (\%) & $90(74.4)$ & $223(65.2)$ & 0.064 \\
\hline Diabetes mellitus, n (\%) & $63(52.1)$ & $182(53.2)$ & 0.828 \\
\hline Dyslipidemia, n (\%) & $81 \quad(66.9)$ & $205(59.9)$ & 0.173 \\
\hline Current or past smoking, $\mathrm{n}(\%)$ & $75(62.0)$ & $157(45.9)$ & 0.002 \\
\hline Dialysis, n (\%) & $5(4.1)$ & $37(10.8)$ & 0.028 \\
\hline Family history, n (\%) & $20(16.5)$ & $65(19.0)$ & 0.545 \\
\hline Left ventricular ejection fraction, \% & $52.57 \pm 10.93$ & $51.61 \pm 13.08$ & 0.531 \\
\hline \multicolumn{4}{|l|}{ Clinical presentation } \\
\hline Stable angina or silent ischemia, $\mathrm{n}(\%)$ & $53(43.8)$ & $226(66.1)$ & - \\
\hline Unstable angina or acute myocardial infraction, $\mathrm{n}(\%)$ & $68(56.2)$ & $116(33.9)$ & $P<0.0001$ \\
\hline
\end{tabular}

ZES, zotarolimus-eluting stents; PES, paclitaxel-eluting stents

There were no significant differences in target vessel location, chronic total occlusion lesions, bifurcation lesions, long lesions, or small vessels between the two groups. The number of calcified lesions in the PES group was significantly higher than in the ZES group $(P=0.0006)$. With respect to lesion complexity determined according to the modified American College of Cardiology / American Heart Association (ACC/AHA) classification, 62.1\% of ZES lesions and $70.3 \%$ of PES lesions were characterized as complex lesions. Although the percentage of complex lesions in the PES group was higher than that in the ZES group, the difference was not significant $(P=0.061)$. However, the percentage of type A lesions in the ZES group was significantly higher than in the PES group $(P=0.002)$, and the percentage of type $\mathrm{C}$ lesions in the PES group was significantly higher than in the ZES group $(P=0.001)$.

The eight-month angiographic follow-up rate was 51\%. At eight months, there were significant differences in the minimal lumen diameter (MLD), percent diameter stenosis (\% DS), and late loss between the two groups. Late loss was significantly higher in the ZES group than in the PES group $(0.82 \pm 0.73 \mathrm{~mm}$ vs $0.47 \pm 0.68 \mathrm{~mm} ; P=0.003)$, although the difference in the restenosis rate between the two groups was not significant $(P=0.191)$. At the one-year clinical follow-up, MI occurred in three patients in the PES group but not in the ZES group, and there were three deaths in the ZES group and six deaths in the PES group, but the differences were not significant $(P=0.328$ and $P=0.512$, respectively; Table 3). Despite the significant difference in late loss, the difference in the TLR rate was not significant between both stent types (ZES : 15 lesions, 9.8\% vs PES : 25 lesions, 5.8\% ; $P=$ 0.092). In addition, the percentage of total MACE was not significantly different between the two groups (ZES : $11.8 \%$ vs PES : $7.2 \% ; P=0.080$ ). 
Table 2. Lesion characteristics and quantitative coronary analysis in all patients

\begin{tabular}{|c|c|c|c|}
\hline & ZES & PES & $P$ value \\
\hline Lesion, $\mathrm{n}$ & 153 & 431 & \\
\hline \multicolumn{4}{|l|}{ Lesion characteristics } \\
\hline \multicolumn{4}{|l|}{ Target vessel } \\
\hline Left main trunk, n (\%) & $16(10.5)$ & $48(11.1)$ & 0.817 \\
\hline Left anterior descending, $\mathrm{n}(\%)$ & $65(42.5)$ & $181(42.0)$ & 0.916 \\
\hline Left circumflex, n (\%) & $37(24.2)$ & $97(22.5)$ & 0.672 \\
\hline Right coronary, n (\%) & $50(35.0)$ & $152(35.3)$ & 0.563 \\
\hline Bifurcation, n (\%) & $64(41.8)$ & $204(47.3)$ & 0.241 \\
\hline Long lesion, n (\%) & $74(48.4)$ & $209(48.5)$ & 0.979 \\
\hline Calcified lesion, n (\%) & $16(10.5)$ & $101(23.4)$ & 0.0006 \\
\hline Small vessel lesion, $\mathrm{n}(\%)$ & $61(39.9)$ & $140(32.5)$ & 0.099 \\
\hline CTO, n (\%) & $12(7.8)$ & $47(10.7)$ & 0.28 \\
\hline \multicolumn{4}{|l|}{ AHA lesion type } \\
\hline $\mathrm{A}, \mathrm{n}(\%)$ & $24(15.7)$ & $31(7.2)$ & 0.002 \\
\hline $\mathrm{B} 1, \mathrm{n}(\%)$ & $34(22.2)$ & $97(22.5)$ & 0.942 \\
\hline $\mathrm{B} 2, \mathrm{n}(\%)$ & $61(39.9)$ & $144(33.4)$ & 0.151 \\
\hline $\mathrm{C}, \mathrm{n}(\%)$ & $34(22.2)$ & $159(36.9)$ & 0.001 \\
\hline type B2 / C, n (\%) & $95(62.1)$ & $303(70.3)$ & 0.061 \\
\hline \multicolumn{4}{|l|}{ QCA } \\
\hline \multicolumn{4}{|l|}{ Pre-PCI } \\
\hline MLD, mm & $0.58 \pm 0.50$ & $0.51 \pm 0.43$ & 0.152 \\
\hline $\mathrm{RD}, \mathrm{mm}$ & $2.97 \pm 1.24$ & $2.67 \pm 0.71$ & 0.863 \\
\hline$\% \mathrm{DS}, \%$ & $85.1 \pm 13.8$ & $80.3 \pm 17.6$ & 0.408 \\
\hline \multicolumn{4}{|l|}{ Post-PCI } \\
\hline $\mathrm{MLD}, \mathrm{mm}$ & $2.65 \pm 0.68$ & $2.62 \pm 0.54$ & 0.708 \\
\hline $\mathrm{RD}, \mathrm{mm}$ & $2.99 \pm 0.57$ & $3.05 \pm 0.59$ & 0.402 \\
\hline \%DS, \% & $12.0 \pm 6.6$ & $14.6 \pm 10.7$ & 0.011 \\
\hline \multicolumn{4}{|l|}{ Follow-up } \\
\hline MLD, mm & $1.89 \pm 0.84$ & $2.11 \pm 0.73$ & 0.041 \\
\hline $\mathrm{RD}, \mathrm{mm}$ & $2.78 \pm 0.50$ & $4.31 \pm 0.50$ & 0.467 \\
\hline \%DS, \% & $32.4 \pm 26.2$ & $25.6 \pm 22.6$ & 0.037 \\
\hline Acute gain, mm & $2.08 \pm 0.59$ & $2.08 \pm 0.59$ & 0.903 \\
\hline Late loss, mm & $0.82 \pm 0.73$ & $0.47 \pm 0.68$ & 0.003 \\
\hline
\end{tabular}

CTO, chronic total occlusion; QCA, quantitative coronary analysis

PCI, percutaneous coronary intervention; MLD, minimal lumen diameter ;

$\mathrm{RD}$, reference diameter; \%DS, \% diameter stenosis

ZES, zotarolimus-eluting stents; PES, paclitaxel-eluting stents

\section{Subgroup analysis stratified by lesion complexity}

When comparing the two groups based on lesion complexity, the baseline patient characteristics stratified by complexity were well balanced between the ZES and PES groups for both simple and complex lesions. However, there was a higher percentage of dialysis patients in the PES group with simple lesions $(P=0.012)$ and a higher percentage of smoking patients 
Table 3. Restenosis and clinical outcomes in all patients

\begin{tabular}{lccc}
\hline \multicolumn{1}{c}{ Variable } & ZES $(\mathrm{n}=153)$ & PES $(\mathrm{n}=431)$ & $P$ value \\
\hline Restenosis, n (\%) & $20(13.1)$ & $76(17.6)$ & 0.191 \\
MACE, n (\%) & $18(11.8)$ & $31(7.2)$ & 0.080 \\
Target lesion revascularization, n (\%) & $15(9.8)$ & $25(5.8)$ & 0.092 \\
Death, n (\%) & $3(2.0)$ & $6(1.4)$ & 0.512 \\
Myocardial infarction, (\%) & $0(0)$ & $3(0.7)$ & 0.328 \\
Target vessel revascularization, n (\%) & $19(12.4)$ & $38(8.8)$ & 0.197 \\
CABG, n (\%) & $0(0)$ & $3(0.7)$ & 0.328 \\
\hline
\end{tabular}

MACE, major adverse cardiac event: all-cause death, myocardial infarction, target lesion revascularization CABG, coronary artery bypass graft; ZES, zotarolimus-eluting stents ; PES, paclitaxel-eluting stents

Table 4. Patient characteristics, stratified by complexity

\begin{tabular}{|c|c|c|c|c|c|c|}
\hline \multirow[b]{2}{*}{ Variable } & \multicolumn{3}{|c|}{ Simple (A / B1) lesion $(n=151)$} & \multicolumn{3}{|c|}{ Complex $(\mathrm{B} 2 / \mathrm{C})$ lesion $(\mathrm{n}=312)$} \\
\hline & ZES & PES & $P$ value & ZES & PES & $P$ value \\
\hline Patients, $\mathrm{n}$ & 44 & 107 & & 77 & 235 & \\
\hline Age, years & $67.96 \pm 11.86$ & $67.57 \pm 9.75$ & 0.837 & $65.43 \pm 13.15$ & $67.25 \pm 10.51$ & 0.217 \\
\hline Male, n (\%) & $34(77.3)$ & $87(81.3)$ & 0.572 & $61(79.2)$ & 186（79.1） & 0.989 \\
\hline \multicolumn{7}{|l|}{ Risk factor } \\
\hline Hypertension, n（\%) & $33(75.0)$ & $73(68.2)$ & 0.408 & $57(74.0)$ & $150(63.8)$ & 0.100 \\
\hline Diabetes mellitus, n (\%) & $25(56.8)$ & $58(54.2)$ & 0.769 & $38(49.4)$ & $124(52.8)$ & 0.603 \\
\hline Dyslipidemia, n（\%) & $34(77.3)$ & $68(63.6)$ & 0.102 & $47(61.0)$ & $137(58.3)$ & 0.671 \\
\hline Current or past smoking, $\mathrm{n}(\%)$ & $31(70.5)$ & $55(51.4)$ & 0.032 & $44(57.1)$ & $102(43.4)$ & 0.036 \\
\hline Dialysis, n (\%) & $0(0)$ & $14(13.1)$ & 0.012 & $5(6.5)$ & $23(9.8)$ & 0.380 \\
\hline Family history, n（\%） & $10(22.7)$ & $24(22.4)$ & 0.968 & $10(13.0)$ & $41(17.4)$ & 0.358 \\
\hline Left ventricular ejection fraction, \% & $53.79 \pm 12.06$ & $54.44 \pm 11.96$ & 0.801 & $51.86 \pm 10.24$ & $50.22 \pm 13.44$ & 0.391 \\
\hline \multicolumn{7}{|l|}{ Clinical presentation } \\
\hline Stable angina or silent ischemia, $\mathrm{n}(\%)$ & $21(47.7)$ & $77(72.0)$ & - & $32(41.6)$ & $150(63.8)$ & - \\
\hline $\begin{array}{l}\text { Unstable angina or acute myocardial } \\
\text { infraction, } \mathrm{n}(\%)\end{array}$ & $23(52.3)$ & $30(28.0)$ & 0.005 & $45(58.4)$ & $85(36.2)$ & 0.001 \\
\hline
\end{tabular}

ZES, zotarolimus-eluting stents; PES, paclitaxel-eluting stents

in the ZES group with both simple and complex lesions $(P=0.032$ and $P=0.036$, respectively; Table 4). There were also significant differences in diagnoses among patients with both simple and complex lesions $(P=0.005$ and $P=0.001$, respectively).

Lesion characteristics and quantitative angiographic analysis data stratified by complexity are listed in Table 5. Lesion locations between the two groups were well matched except for the higher percentage of left anterior descending locations of simple lesions in the ZES group $(P=0.002)$ and right coronary artery locations of simple lesions in the PES group 
Table 5. Lesion characteristics and quantitative coronary analysis, stratified for complexity

\begin{tabular}{|c|c|c|c|c|c|c|}
\hline & \multicolumn{3}{|c|}{ Simple $(A / B 1)$ lesion $(n=186)$} & \multicolumn{3}{|c|}{ Complex $(B 2 / C)$ lesion $(\mathrm{n}=312)$} \\
\hline & ZES & PES & $P$ value & ZES & PES & $P$ value \\
\hline Lesion, $\mathrm{n}$ & 58 & 128 & & 95 & 303 & \\
\hline \multicolumn{7}{|l|}{ Lesion characteristics } \\
\hline \multicolumn{7}{|l|}{ Target vessel } \\
\hline Left main trunk, n (\%) & $2(3.4)$ & $2(1.6)$ & 0.412 & $14(14.7)$ & $46(15.2)$ & 0.916 \\
\hline Left anterior descending, $\mathrm{n}(\%)$ & $31(53.4)$ & $38(29.7)$ & 0.002 & $34(35.8)$ & $143(47.2)$ & 0.051 \\
\hline Left circumflex, n (\%) & $11(19.0)$ & $29(22.7)$ & 0.570 & $26(27.4)$ & $68(22.4)$ & 0.324 \\
\hline Right coronary, n (\%) & $15(25.9)$ & $60(46.9)$ & 0.007 & $35(36.8)$ & $92(30.4)$ & 0.237 \\
\hline Bifurcation, n (\%) & $11(19.0)$ & $34(26.6)$ & 0.262 & $53(55.7)$ & $170(56.1)$ & 0.957 \\
\hline Long lesion, $\mathrm{n}(\%)$ & - & - & - & $55(23.9)$ & $55(23.9)$ & 0.140 \\
\hline Calcified lesion, n (\%) & $0(0)$ & $19(14.8)$ & 0.002 & $16(16.8)$ & $82(27.1)$ & 0.044 \\
\hline Small vessel lesion, $\mathrm{n}(\%)$ & $19(32.8)$ & $32(25.0)$ & 0.272 & $42(44.2)$ & $108(35.6)$ & 0.133 \\
\hline CTO, n (\%) & - & - & - & $12(12.6)$ & $47(15.5)$ & 0.491 \\
\hline \multicolumn{7}{|l|}{ QCA } \\
\hline \multicolumn{7}{|l|}{ Pre-PCI } \\
\hline MLD, mm & $0.81 \pm 0.51$ & $0.70 \pm 0.43$ & 0.246 & $0.44 \pm 0.44$ & $0.55 \pm 0.43$ & 0.136 \\
\hline $\mathrm{RD}, \mathrm{mm}$ & $2.78 \pm 0.60$ & $2.64 \pm 0.64$ & 0.273 & $2.62 \pm 0.66$ & $2.69 \pm 0.77$ & 0.605 \\
\hline \%DS, \% & $72.1 \pm 15.2$ & $75.6 \pm 13.4$ & 0.209 & $82.8 \pm 16.7$ & $78.5 \pm 19.5$ & 0.154 \\
\hline \multicolumn{7}{|l|}{ Post-PCI } \\
\hline MLD, mm & $2.77 \pm 0.62$ & $2.76 \pm 0.41$ & 0.897 & $2.57 \pm 0.45$ & $2.55 \pm 0.61$ & 0.856 \\
\hline $\mathrm{RD}, \mathrm{mm}$ & $3.09 \pm 0.64$ & $3.10 \pm 0.48$ & 0.875 & $2.93 \pm 0.51$ & $3.01 \pm 0.55$ & 0.405 \\
\hline$\% \mathrm{DS}, \%$ & $10.3 \pm 5.7$ & $11.4 \pm 7.5$ & 0.392 & $13.1 \pm 7.0$ & $14.3 \pm 13.7$ & 0.466 \\
\hline \multicolumn{7}{|l|}{ Follow-up } \\
\hline MLD, mm & $2.19 \pm 0.63$ & $2.28 \pm 0.66$ & 0.551 & $1.71 \pm 0.91$ & $2.08 \pm 0.78$ & 0.029 \\
\hline $\mathrm{RD}, \mathrm{mm}$ & $2.81 \pm 0.66$ & $2.89 \pm 0.45$ & 0.544 & $2.75 \pm 0.48$ & $2.77 \pm 0.67$ & 0.890 \\
\hline$\% \mathrm{DS}, \%$ & $22.1 \pm 13.3$ & $21.5 \pm 18.5$ & 0.857 & $38.8 \pm 30.0$ & $25.7 \pm 24.3$ & 0.017 \\
\hline Acute gain, mm & $1.95 \pm 0.59$ & $2.04 \pm 0.56$ & 0.443 & $2.15 \pm 0.58$ & $2.04 \pm 0.60$ & 0.272 \\
\hline Late loss, mm & $0.59 \pm 0.45$ & $0.49 \pm 0.57$ & 0.431 & $0.97 \pm 0.83$ & $0.48 \pm 0.72$ & 0.002 \\
\hline
\end{tabular}

CTO, chronic total occlusion; QCA, quantitative coronary analysis PCI, percutaneous coronary intervention; MLD, minimal lumen diameter; RD, reference diameter \%DS, \% diameter stenosis; ZES, zotarolimus-eluting stents; PES, paclitaxel-eluting stents

$(P=0.007)$. As to complex lesions, the percentage of left circumflex lesions in the PES group was higher, but the difference was not significant $(P=0.051)$. The number of calcified simple and complex lesions in the PES group was significantly higher than in the ZES group $(P=0.002$ and $P=0.044$, respectively).

When comparing QCA data among the patients with simple lesions, no differences were found between the ZES and PES groups, including late loss. Conversely, in patients with complex lesions, there were significant differences in follow-up MLD (ZES : $1.71 \pm 0.91 \mathrm{~mm}$ vs PES : $2.08 \pm 0.78 \mathrm{~mm} ; P=0.029)$, \%DS (ZES : $38.79 \% \pm 29.99 \%$ vs PES : $25.71 \% \pm$ 24.28\%; $P=0.017$ ), and late loss (ZES : $0.97 \pm 0.83 \mathrm{~mm}$ vs PES : $0.48 \pm 0.72 \mathrm{~mm} ; P=0.002$ ). 
Table 6. Restenosis and clinical outcomes stratified by complexity

\begin{tabular}{lcccccc}
\hline & Simple $(\mathrm{A} / \mathrm{B} 1)$ & lesion $(\mathrm{n}=186)$ & \multicolumn{2}{c}{ Complex $(\mathrm{B} 2 / \mathrm{C})$} & lesion $(\mathrm{n}=398)$ \\
\hline \multicolumn{1}{c}{ Variable } & ZES $(\mathrm{n}=58)$ & PES $(\mathrm{n}=128)$ & $P$ value & ZES $(\mathrm{n}=95)$ & PES $(\mathrm{n}=303)$ & $P$ value \\
\hline Restenosis, n (\%) & $2(3.4)$ & $23(18.0)$ & 0.007 & $19(20)$ & $53(17.5)$ & 0.580 \\
& $1(1.7)$ & $12(9.4)$ & 0.058 & $18(17.9)$ & $20(6.6)$ & 0.0004 \\
MACE, n (\%) & $0(0)$ & $9(7.0)$ & 0.038 & $15(15.8)$ & $16(5.3)$ & 0.009 \\
$\begin{array}{l}\text { Target lesion revascularization, } \\
\text { n (\%) }\end{array}$ & $1(1.7)$ & $1(0.8)$ & 0.513 & $3(3.2)$ & $6(2.0)$ & 0.501 \\
$\begin{array}{l}\text { Death, n (\%) } \\
\text { Myocardial infarction, (\%) }\end{array}$ & $0(0)$ & $2(1.6)$ & 0.361 & $0(0)$ & $2(0.7)$ & 0.427 \\
$\begin{array}{l}\text { Target vessel revascularization } \\
\text { n (\%) }\end{array}$ & $1(1.7)$ & $11(8.6)$ & 0.077 & $18(18.9)$ & $27(8.9)$ & 0.007 \\
CABG, n (\%) & $0(0)$ & $0(0)$ & - & $0(0)$ & $3(1.0)$ & 0.319 \\
\hline
\end{tabular}

MACE, major adverse cardiac event: all-cause death, myocardial infarction, target lesion revascularization CABG, coronary artery bypass graft; ZES, zotarolimus-eluting stents ; PES, paclitaxel-eluting stents

Restenosis rates and clinical outcomes stratified by complexity are summarized in Table 6 . Among the patients with simple lesions, the TLR rate in the ZES group was significantly lower than that in the PES group (ZES : 0\% vs PES : 7.0\%; $P=0.038$ ). Although there was a higher percentage of MACE in the PES group (ZES: 1.7\% vs PES: 9.4\%), the difference was not significant $(P=0.058)$. In the complex lesion subgroup, the TLR rate in the ZES group was significantly higher than in the PES group (ZES: $15.8 \%$ vs PES : 5.3\%; $P=0.009)$. In addition, the percentage of total MACE in the ZES group with complex lesions was significantly higher than in the PES group (ZES: 17.9\% vs PES : $6.6 \% ; P=0.0004)$.

\section{Multivariate analysis}

Multivariate logistic regression analysis showed that dialysis [odds ratio (OR) : $35.54 ; 95 \%$ CI : $3.15-400.67 ; P=0.039]$ and pre-MLD (OR : $0.036 ; 95 \% \mathrm{CI}: 0.002-0.541 ; P=0.016$ ) were independent predictors of TLR in lesions treated with ZESs. In contrast, no factors predicted TLR in patients with lesions treated with PESs.

\section{Discussion}

Although DESs are now widely used, the clinical efficacy of ZES implantation still remains unclear, as it has been reported that the late loss in patients treated with ZESs is higher than that observed in patients treated with other DESs ${ }^{7)}$. There is limited information about the angiographic and clinical outcomes of patients treated with first-generation DESs and ZESs, and to the best of our knowledge, few studies have focused on examining these variables based on differential lesion complexity. We therefore retrospectively compared the angiographic and clinical outcomes of patients treated with the second-generation 
DES, ZES, and the first-generation DES, PES, based on lesion complexity.

In our study, approximately $73.8 \%$ of the study population had high-risk ACC / AHA type B2 / C coronary lesions. With respect to clinical diagnosis and regardless of lesion complexity, the percentage of ACS patients was higher in the ZES group than in the PES group. In addition, there were significant differences between the ZES and PES groups with respect to lesion characteristics: the percentage of type A lesions was significantly higher in the ZES group than in the PES group. However, the percentages of type $\mathrm{C}$ lesions and calcified lesions in the PES group were significantly higher than in the ZES group. Additionally, there were significant differences between the ZES and PES groups with respect to the percentage of dialysis patients. Several explanations exist for these differences. Firstly, patients in this study were not randomly assigned to a given DES type. In our hospital, the use of ZESs was preferred for ACS cases over other DESs. Similarly, the use of PESs was preferred for dialysis cases over other DESs, as PESs are reportedly more effective in dialysis cases $^{9)}$. It is possible that there could be a relationship between the higher percentage of dialysis and lesion calcification in the PES group. Secondly, several randomized studies have demonstrated the superiority of DESs over BMSs for the treatment of ACS ${ }^{10)}$. However, during the era of first-generation DESs, the use of DESs for ACS cases was debated due to the risk of late and very late stent thrombosis (VLST $)^{11-13)}$. Therefore, the use of BMSs for ACS cases instead of first-generation DESs, such as sirolimus-eluting stents (SESs) and PESs, is preferred in our hospital. Thirdly, everolimus-eluting stents (EESs ; Abbott Vascular, Santa Clara, CA, USA) have been available in Japan since February 2010, and they are used more commonly than ZESs in complex cases in our hospital.

Upon analyzing the angiographic data after ZES implantation, the late loss was found to be greater $(0.82 \pm 0.73 \mathrm{~mm})$ in the current study than previously reported $(0.61 \pm$ $0.49 \mathrm{~mm})^{7)}$. In addition, the late loss in the ZES group was significantly greater than that in the PES group. There are three reasons for the greater late loss observed in the ZES group compared to the PES group ${ }^{4)}$. Firstly, the increased neointimal hyperplasia associated with ZESs is due to differences in the pharmacological activity of zotarolimus compared to other DESs. Secondly, the more rapid elution kinetics of zotarolimus from the phosphorylcholine polymer, which results in 95\% elution over approximately 15 days ${ }^{14)}$, influences the biological efficacy of ZESs compared to the slower release of other DESs. Thirdly, there are differences in the biological responses to either the stent or the phosphorylcholine polymer itself. Whereas the late loss seen in the ZES group was overall significantly greater than in the PES group in our study, the difference in the TLR rate was not significant (ZES : 9.8\% vs PES : $5.8 \% ; P=0.092$ ). However, the TLR rate in the ZES group was relatively higher than previously reported $\left(4.5 \%{ }^{15)}\right.$ and $\left.4.9 \%{ }^{16)}\right)$.

In the lesion complexity subgroups divided according to ACC/AHA lesion type, ZESs resulted in excellent outcomes for A/B1 lesions, which were classified as "simple" lesions. However, for B2/C lesions, which were classified as "complex" lesions, the incidence of 
TLR was significantly higher in the ZES group than in the PES group. The complexity of lesions increased the incidence of TLR in the ZES group. Lotan et al investigated and compared real-world outcomes of ZESs based on data from the E-Five Registry. Patients ranged from those requiring standard use ZES treatment for simple lesions to those needing extended use for lesions with complex characteristics ${ }^{15)}$. They reported that the TLR rate was significantly higher in the extended-use group compared to the standard-use group (standard : $2.8 \%$ vs extended: $5.0 \% ; P<0.001$ ).

A number of factors associated with a higher risk of TLR in ZES-treated patients have been reported in many studies. For example, Mehta et al compared patients treated with ENDEAVOR I, II, or III who required TLR to patients who did not require TLR ${ }^{16)}$. Multivariate analysis suggested that older age (OR: 1.03;95\% CI : 1.00-1.06), male sex (OR : 1.79; 95\% CI : 0.88-3.65), and longer lesion length (OR : 1.03; 95\% CI : 0.99-1.07) were independent risk factors for TLR after ZES implantation ${ }^{16)}$. In our study, multivariate analysis identified pre-MLD and dialysis as predictors of TLR in the ZES group. It is well known that patients on dialysis have lesions with more complex characteristics, such as increased media thickness, massive calcification of coronary lesions, and multi-vessel disease, compared to patients not on dialysis. To the best of our knowledge, no study has focused on dialysis in ZES-treated patients. The reasons for this remain unclear. Further studies will be necessary to confirm these results.

Many studies have compared ZESs with other $\mathrm{DESs}^{3,4,8)}$, but few studies have focused on differential lesion complexity. Leon et al concluded that ZESs have similar levels of clinical safety and efficacy as PESs in simple and medium complexity single de novo lesions ${ }^{3)}$. Similarly, Stefanini et al compared ZESs with EESs on the basis of lesion complexity and reported that the newer-generation ZESs and EESs proved to be safe and effective, regardless of complexity, with similar clinical and angiographic outcomes obtained for both stent types over one year ${ }^{8)}$. However, the definitions of complexity used in these articles were slightly different from the definitions used in this report. For example, in the latter article, the definition of "complex" included characteristics such as acute MI within $72 \mathrm{~h}$, left ventricular ejection fractions less than $30 \%$, renal insufficiency or failure, treatment of bifurcations, saphenous vein grafts, arterial grafts, in-stent restenosis, unprotected left main lesions, treatment of more than two vessels, lesion lengths over $27 \mathrm{~mm}$, more than one lesion/vessel, lesion with thrombus, or lesion with total occlusion ${ }^{8)}$. As described in the Methods section, we defined A/B1 lesions as "simple" lesions and B2/C lesions as "complex" lesions. By isolating complex lesions from lesions with the clinical characteristics described by Stefanini et $a l^{8)}$, we were able to design this study such that the clinical outcomes attributable to specific types of lesion complexity could be assessed. Therefore, it is difficult to simply compare the results from other studies to our results.

Although the decision to use ZESs should not be negatively influenced by lesion complexity, a greater late loss was found to be associated with a greater risk for TLR. In addi- 
tion, both the mid-term outcomes and the long-term outcomes, such as late stent thrombosis and VLST, should be considered. Recent studies using IVUS ${ }^{17)}$, optical coherence tomography ${ }^{18)}$, and angioscopy ${ }^{19)}$ reported that DESs demonstrated reduced late loss and had an inhibitory effect on neointimal hyperplasia but might be associated with a risk of late stent thrombosis or VLST due to incomplete neointimal coverage ${ }^{19)}$. According to these articles, neointimal coverage after ZES implantation was nearly complete, which was similar to the pattern observed with BMSs when compared to the first-generation DESs. A pooled analysis with a long-term follow-up of ZES-treated patients indicated that the frequency of VLST was less than 1\%, which was similar to results observed after BMS treatment ${ }^{20)}$. Kang et al compared ZESs with SESs, and PESs with IVUS and reported that ZESs had no late stent malpositions ${ }^{21)}$. Although a larger amount of neointimal hyperplasia leads to the need for TLR, the coverage of ZES struts with neointimal hyperplasia may offer a protective advantage for early vessel healing. Thus, the greater late loss of ZESs may not translate into worse clinical outcomes, and is therefore not necessarily a disadvantage of ZESs. In addition, it is unknown whether there are differences in late safety outcomes specific to the different types of DESs relative to the duration of dual antiplatelet therapy (DAPT). It is believed that the duration of DAPT after ZES implantation may be shorter compared to other DESs due to the more rapid elution kinetics of zotarolimus from the phosphorylcholine polymer ${ }^{22)}$. The overall attributes of ZESs versus other stents must be considered when making decisions in clinical practice.

\section{Study limitations}

This study has several limitations that should be noted. Firstly, this study was conducted at a single center, was retrospective, was relatively small, and patients were not randomly assigned to given DES types. The unblended evaluation of stent type was at the discretion of the operators. Secondly, we only analyzed the patients up to one year post-implantation and did not investigate long-term follow-ups. A one-year follow-up may be too short to capture late events, such as VLST, after implantation of these DESs. A longer follow-up is necessary to assess the safety and efficacy of ZES implantations. Thirdly, the eight-month angiographic follow-up rate was relatively low (51\%) compared to previous reports.

\section{Conclusion}

Our study suggested that patients treated with ZESs demonstrated excellent mid-term angiographic and clinical outcomes for simple lesions compared to those treated with PESs, but it is necessary to implant ZESs carefully in complex lesions. However, the decision to use ZESs should not be negatively influenced by lesion complexity alone. Both mid-term and long-term outcomes should be considered. Therefore, the overall attributes of ZESs versus other DESs must be considered when making decisions in clinical practice. 


\section{References}

1) Kirtane AJ, Gupta A, Iyengar S, Moses JW, Leon MB, Applegate R, Brodie B, Hannan E, Harjai K, Jensen LO, Park SJ, Perry R, Racz M, Saia F, Tu JV, Waksman R, Lansky AJ, Mehran R and Stone GW: Safety and efficacy of drug-eluting and bare metal stents: comprehensive meta-analysis of randomized trials and observational studies. Circulation 119 : 3198-3206 (2009)

2) Morice MC, Serruys PW, Sousa JE, Fajadet J, Ban Hayashi E, Perin M, Colombo A, Schuler G, Barragan P, Guagliumi G, Molnar F, Falotico R and RAVEL Study Group. Randomized study with the sirolimus-coated Bx velocity balloon-expandable stent in the treatment of patients with de novo native coronary artery lesions: A randomized comparison of a sirolimus-eluting stent with a standard stent for coronary revascularization. $N$ Engl J Med 346 : 1773-1780 (2002)

3) Leon MB, Mauri L, Popma JJ, Cutlip DE, Nikolsky E, O’Shaughnessy C, Overlie PA, McLaurin BT, Solomon SL, Douglas JS Jr, Ball MW, Caputo RP, Jain A, Tolleson TR, Reen BM 3rd, Kirtane AJ, Fitzgerald PJ, Thompson K, Kandzari DE and ENDEAVOR IV Investigators: A randomized comparison of the ENDEAVOR zotarolimus-eluting stent versus the TAXUS paclitaxel-eluting stent in de novo native coronary lesions 12-month outcomes from the ENDEAVOR IV trial. J Am Coll Cardiol 55 : 543-554 (2010)

4) Kandzari DE, Leon MB, Popma JJ, Fitzgerald PJ, O’Shaughnessy C, Ball MW, Turco M, Applegate RJ, Gurbel PA, Midei MG, Badre SS, Mauri L, Thompson KP, LeNarz LA, Kuntz RE and ENDEAVOR III Investigators: Comparison of zotarolimus-eluting and sirolimus-eluting stents in patients with native coronary artery disease : a randomized controlled trial. J Am Coll Cardiol 48 : 2440-2447 (2006)

5) Fajadet J, Wijns W, Laarman GJ, Kuck KH, Ormiston J, Munzel T, Popma JJ, Fitzgerald PJ, Bonan R, Kuntz RE and ENDEAVOR II Investigators: Randomized, double-blind, multicenter study of the Endeavor zotarolimus-eluting phosphorylcholine-encapsulated stent for treatment of native coronary artery lesions : clinical and angiographic results of the ENDEAVOR II trial. Circulation $114: 798-806$ (2006)

6) Mauri L, Massaro JM, Jiang S, Meredith I, Wijns W, Fajadet J, Kandzari DE, Leon MB, Cutlip DE and Thompson KP: Long-term clinical outcomes with zotarolimus-eluting versus bare-metal coronary stents. JACC Cardiovasc Interv 3 : 1240-1249 (2010)

7) Gershlick A, Kandzari DE, Leon MB, Wijns W, Meredith IT, Fajadet J, Popma JJ, Fitzgerald PJ, Kuntz RE and ENDEAVOR Investigators: Zotarolimus-eluting stents in patients with native coronary artery disease : clinical and angiographic outcomes in 1,317 patients. Am J Cardiol 100(8B) : 45M-55M (2007)

8) Stefanini GG, Serruys PW, Silber S, Khattab AA, van Geuns RJ, Richardt G, Buszman PE, Kelbæk H, van Boven AJ, Hofma SH, Linke A, Klauss V, Wijns W, Macaya C, Garot P, Di Mario C, Manoharan G, Kornowski R, Ischinger T, Bartorelli AL, Gobbens $\mathrm{P}$ and Windecker S: The impact of patient and lesion complexity on clinical and angiographic outcomes after revascularization with zotarolimus- and everolimus-eluting stents : a substudy of the RESOLUTE All Comers Trial (a randomized comparison of a zotarolimus-eluting stent with an everolimus-eluting stent for percutaneous coronary intervention). J Am Coll Cardiol 57 : 2221-2232 (2011)

9) Otsuka M, Toyofuku M, Watanabe N, Motoda C, Kawase T, Takeda R, Mito S, Tamekiyo H, Okimoto T, Hirao H, Muraoka Y, Ueda H, Masaoka Y and Hayashi Y: Clinical usefulness of drug-eluting stents in the treatment of dialysis patients with coronary artery disease. EuroIntervention 6:754-759 (2011)

10) Mauri L, Silbaugh TS, Garg P, Wolf RE, Zelevinsky K, Lovett A, Varma MR, Zhou Z and Normand SL: Drug-eluting or bare-metal stents for acute myocardial infarction. N Engl J Med 359: 1330-1342 (2008)

11) Feres F, Costa JR Jr and Abizaid A : Very late thrombosis after drug-eluting stents. Catheter Cardiovasc Interv $68: 83-88(2006)$

12) Cook S, Wenaweser $P$, Togni M, Billinger M, Morger C, Seiler C, Vogel R, Hess O, Meier B and Windecker $\mathrm{S}$ : Incomplete stent apposition and very late stent thrombosis after drug-eluting stent implantation. Circulation $115: 2426-2434(2007)$

13) Kubo $T$, Imanishi $T$, Kitabata $H$, Kuroi A, Ueno $S$, Yamano $T$, Tanimoto $T$, Matsuo $Y$, Masho $T$, Takarada $S$, Tanaka A, Nakamura N, Mizukoshi M, Tomobuchi Y and Akasaka T: Comparison of vascular response after 
sirolimus-eluting stent implantation between patients with unstable and stable angina pectoris: a serial optical coherence tomography study. JACC Cardiovasc Imaging 1:475-484 (2008)

14) Cirillo P, De Rosa S, Di Palma V, De Rosa R, Maietta P, Piscione F and Chiariello M: Different vascular response to concurrent implantation of sirolimus- and zotarolimus-eluting stents in the same vessel. Heart Vessels $24: 313-316$ (2009)

15) Lotan C, Meredith IT, Mauri L, Liu M and Rothman MT and E-Five Investigators : Safety and effectiveness of the Endeavor zotarolimus-eluting stent in real-world clinical practice: 12-month data from the E-Five registry. JACC Cardiovasc Interv 2 : 1227-1235 (2009)

16) Mehta RH, Leon MB, Sketch MH Jr and ENDEAVOR II Continued Access Registry: The relation between clinical features, angiographic findings, and the target lesion revascularization rate in patients receiving the endeavor zotarolimus-eluting stent for treatment of native coronary artery disease : an analysis of ENDEAVOR I, ENDEAVOR II Continued Access Registry, and ENDEAVOR III. Am J Cardiol 100(8B) : 62M-70M (2007)

17) Miyazawa A, Ako J, Hongo Y, Hur SH, Tsujino I, Courtney BK, Hassan AH, Kandzari DE, Honda Y, Fitzgerald PJ and ENDEAVOR III Investigators: Comparison of vascular response to zotarolimus-eluting stent versus sirolimus-eluting stent: intravascular ultrasound results from ENDEAVOR III. Am Heart J 155 : 108-113 (2008)

18) Kim JS, Jang IK, Fan C, Kim TH, Kim JS, Park SM, Choi EY, Lee SH, Ko YG, Choi D, Hong MK and Jang $\mathrm{Y}$ : Evaluation in 3 months duration of neointimal coverage after zotarolimus-eluting stent implantation by optical coherence tomography: the ENDEAVOR OCT trial. JACC Cardiovasc Interv 2 : 1240-1247 (2009)

19) Kotani J, Awata M, Nanto S, Uematsu M, Oshima F, Minamiguchi H, Mintz GS and Nagata S: Incomplete neointimal coverage of sirolimus-eluting stents : angioscopic findings. J Am Coll Cardiol 47 : 2108-2111 (2006)

20) Cutlip DE, Baim DS, Ho KK, Popma JJ, Lansky AJ, Cohen DJ, Carrozza JP Jr, Chauhan MS, Rodriguez O and Kuntz RE: Stent thrombosis in the modern era: a pooled analysis of multicenter coronary stent clinical trials. Circulation $103:$ 1967-1971 (2001)

21) Kang SJ, Mintz GS, Park DW, Lee SW, Kim YH, Lee CW, Han KH, Kim JJ, Park SW and Park SJ : Comparison of zotarolimus-eluting stents with sirolimus-eluting and paclitaxel-eluting stents: intimal hyperplasia and vascular changes assessed by volumetric intravascular ultrasound analysis. Circ Cardiovasc Interv 4: 139-145 (2011)

22) Kandzari DE, Barker CS, Leon MB, Mauri L, Wijns W, Fajadet J and Mehran R: Dual antiplatelet therapy duration and clinical outcomes following treatment with zotarolimus-eluting stents. JACC Cardiovasc Interv 4 : 1119-1128 (2011) 